\title{
Investigating the influence of highway traffic flow condition on pollutant emissions using driving simulators
}

\author{
M. R. De Blasiis ${ }^{1}$, M. Di Prete $^{2}$, C. Guattari ${ }^{1}$, V. Veraldi ${ }^{1}$, \\ G. Chiatti ${ }^{1} \&$ F. Palmieri ${ }^{1}$ \\ ${ }^{I}$ Department of Engineering, Roma Tre University, Italy \\ ${ }^{2}$ Istituto I.R.I.D.E., Rome, Italy
}

\begin{abstract}
In the last 20 years the attention of international organizations towards air pollution has been improved, leading to definition of laws and regulations. In order to evaluate strategies and policies, forecasting tools have been adopted by institutions. Currently, the estimation of traffic emissions is based on static models, in which the amount of pollutant is computed as a function of average parameters obtained on a single road stretch.

The well-known traffic increase of recent years has significantly changed the actual flow conditions, producing a strong rise of interferences. As this facet affects the operating condition of each vehicle, the use of a standard emission model at high traffic interference can lead to some inaccuracies. In such cases, instantaneous emission models introduce deeper capabilities; essentially, the pollutant prediction is directly tied to the engine vehicle operation point in reallike traffic condition. This second modelling approach has been adopted in the current work. A complete lumped parameter vehicle model has been built to be used as a virtual on-road emission/fuel consumption test unit. Investigations have highlighted the dependence of emission level and fuel consumption on drivers' behaviour; indeed, the analysis took advantage of the experiments carried out in the virtual reality laboratory: on a typical highway geometry, characterized by a dual lane carriageway with three lanes each, three different flow conditions have been simulated. Once the relationship between highway interference level and drivers' behaviour has been evidenced (in terms of emissions and fuel consumption), a relation between highway interference level and emissions/fuel consumption has been highlighted. Finally, in order to assess the differences
\end{abstract}


between static and instantaneous emission models, a comparative analysis has been carried out.

Keywords: emission factors, emission models. driving simulator, driver's behaviour.

\section{Introduction}

Emission models are based on mathematical formulations of the existing relationships between emissions and variables on which these emissions depend. They can be classified into three categories: average speed models, traffic situation models and instantaneous (modal) (Ajtay and Weilenmann [1]). Static models evaluate the average value of pollutant emissions within a defined time. However, there are many cases where the average speed is not representative of the real functioning of the investigated infrastructure. In urban areas, for example, where the sequence of intersections can be high, the average speed cannot be taken into account as a significant parameter of the emissions that occur along the stretch of road studied. In order to consider models which measure the instantaneous speed profile, acceleration or deceleration and vehicle emission along a single stretch of road, it is necessary to move from average parameters to instantaneous values. These models are called dynamic models.

Dynamic models are based on a set of parameters designed to evaluate instantaneous emissions as a function of specific significant variables. The functions themselves vary depending on the different kinematic motions taken by the drivers in the different traffic flow and geometrical conditions. As demonstrated by Liu et al. [2], there was an immediate need to look at the emission phenomenon in terms of instantaneous values. To better understand how the traffic control could affect vehicle emissions, a novel TRaffic And Vehicle Emission Linkage (TRAVEL) approach was developed based on local traffic activity and emission data. The results were validated by traffic and air quality monitoring data during the Olympics (2008), as well as other emission inventory studies.

It is well known that different traffic flow conditions lead to different driving styles, reflected by average speed, acceleration and deceleration values. It is also known that frequent speed-change induces high emission levels. Trozzi et al. [3] presented a study on sensitivity finalizing the analysis of the influence of speed on emissions. The study discusses the aspects linked to the speed in the application of the CORINAIR methodology to urban areas, in particular the introduction of a speed frequency distribution by vehicle category (Thirteen classes with range $10 \mathrm{~km} / \mathrm{h}$ ).

Moreover, Gense [4] showed the effects of different driving styles on fuel consumption and tail pipe emissions in modern passenger cars. The final goal of the investigation was to come up with practical tips for energy conscious driving, also addressing the effects of driving styles on tail pipe emissions. Furthermore, it is also shown that the rise of emission levels due to drivers' behaviour is a very sensitive issue for many governments, because the close connection between the two directly results in the release of air pollutants. 
In Van Mierlo et al. [5] the influence on vehicle emissions and energy consumption of different vehicle parameters and driving styles, as well as traffic measures taken in order to increase transport safety or to reduce traffic jams is described. This allowed the Flemish Regional Government to perform more realistic modelling of the impact of transport on air pollution. Different driving styles (sportive, EcoDriving, etc.) were measured on-road and evaluated on a roll-bench. Typical speed profiles corresponding to different traffic measures such as roundabouts, phased traffic lights, etc., were also recorded at different locations in the Flemish Region. All data was distilled into small driving cycles, representative of a certain traffic situation or driving style, and repeated on a rollbench to measure the emissions in controlled circumstances. It was evident that average speed values were not very representative of particular traffic conditions.

Corsmeier et al. [6] researched the quality of an emission calculation model. This was based on emission factors measured on roller test stands and statistical traffic data source strength, as well as the emission factors calculated from realworld exhaust gas concentration differences measured upwind and downwind of a motorway in southwest Germany. In this research, both gaseous and particulate emissions were taken into account and detailed traffic census data was taken during the measurements. The main conclusion by the model was the underestimation of $\mathrm{CO}$ and $\mathrm{NOx}$ source strengths. On average, 23\% of $\mathrm{CO}$ and $17 \%$ for NOx was found.

Smit et al. [7] on the other hand studied the lack of accuracy related to models that are based on the analysis of standard driving cycles and standard emissions. The study presents a meta-analysis of 50 other studies dealing with the validation of various types of traffic emission models, including 'average speed', 'traffic situation', 'traffic variable', 'cycle variable', and 'modal' models. With the same aim, de Haan and Keller [8] have shown the results of a research carried out using 'instantaneous' high-resolution $(1 \mathrm{~Hz})$ emission data for the estimation of passenger car emissions during real-world driving. Extensive measurements of 20 Euro 1 gasoline passenger cars have been used to predict emission factors for standard (i.e. legislative) as well as non-standard (i.e. real-world) driving patterns. Emission level predictions based upon chassis dynamometer tests over standard driving cycles significantly underestimate emission levels during realworld driving were shown.

Ajtay et al. [9] developed a microscopic instantaneous emission model to address the needs of researchers and policy makers on local levels. This model aims to predict vehicle fuel consumption and emissions for a given speed profile, for various scenarios. The need to study more in depth the speed profile and its variation to calculate emission is very evident, since the accurate study of the real driving cycle depends on the accuracy and the reliability of the prediction of emission levels. For this reason, emission models based on instantaneous speed values deduced from the study of a real driving cycle were combined with the traffic simulation models.

Int Panis et al. [10] studied the effects of active speed management on trafficinduced emissions. In particular, the traffic emissions caused by acceleration and deceleration of vehicles were modeled based on an instantaneous emission 
model integrated with a microscopic traffic simulation model. The study suggests that the analysis of the environmental impacts of any traffic management and control policies is a complex issue and requires detailed analysis of not only their impact on average speed, but also on other aspects of vehicle operation; such as acceleration and deceleration. Franco et al. [11] analyzed many different models that allow to measure road vehicle emissions. The paper shows a review of the ways in which Emissions Factors can be calculated. The authors highlight how data can be derived from test carried out under controlled conditions (engine and chassis dynamometer measurements using standard driving cycles) and measurements under real-world operation.

As currently, the estimation of traffic emissions is based on static models, the aim of this research is to highlight the importance of driving styles in order to evaluate emission factors (EFs) under different traffic flow conditions; the details of the method are described in the following section.

\section{Methodology}

This study has been developed providing a comparison between the static and dynamic models using driving simulator data. In order to approach this complex issue, three different advanced tools have been used. The first one is the Driving Simulator, which is able to reproduce the same driving conditions - in terms of traffic conditions, geometrical characteristics and surroundings - for different drivers. The second one is a complete lumped parameter vehicle model, implemented in the AMESim environment [12]. This tool has been coupled to the former on the basis of the parameters which characterize drivers' behaviour (speed profile) and it has been used to compute the instantaneous EFs values; in a similar approach, the engine behavior in terms of consumption and emissions has been related in previous works $[13,14]$ to the fuel injection strategy, which is obviously linked to the driver style. Through the third tool, the static model COPERT 4 [15], the EFs have been calculated as well. Finally, the comparison between the EFs values carried out by dynamic model and static model has been analyzed.

\section{System description and modelling}

\subsection{STI driving simulator}

In order to characterize drivers' behaviour during driving, STI driving simulator has been used at the Virtual Reality laboratory of Inter Universities Research Centre for Road Safety (CRISS) (Figure 1). The reliability of full instrumentation has been fully validated (Bella [16], Benedetto et al. [17]).

The simulator is installed inside a real vehicle to have the best feeling of reality during the experiments. The images are projected in front of the car and sideways just to cover the visual angle of $135^{\circ}$ and the sound speakers are inserted inside the engine to emulate the acoustic environment at the best. 


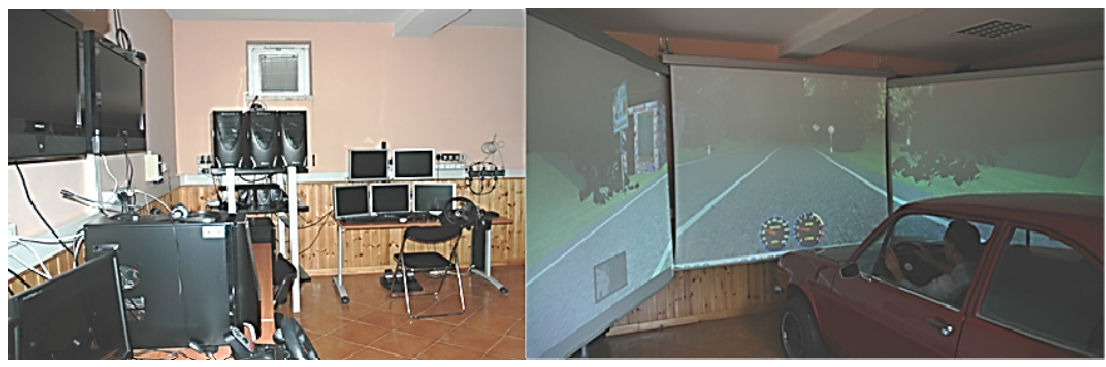

Figure 1: $\quad$ STI driving simulator.

\subsubsection{Sample of drivers and statistical validation}

An homogeneous sample of subjects has been selected and the same driving conditions were performed for each driver to avoid biasing of results induced by: driver attitude, driving experience, age, level of stress, emotional state or neurocognitive status or by other factors. Twenty-two subjects (10 women and 12 men, mean age of 40 years, age range 20-60) were recruited. All participants had a valid Italian driving licence. This sample of drivers has been fully validated through a statistical method based on the verification of the stability of average parameters - the convergence of the average values of speed kept by each driver - it has been assessed that the number of participants is significant from a statistical point of view, and it assures a correct statistic data interpretation (Benedetto et al. [17]). Moreover, to exclude outliers, Chauvenet criterion has been used. This criterion is a statistical method useful to evaluate the reliability of the output of simulation data (Benedetto et al. [17]).

\subsubsection{Road scenario}

The drivers were requested to drive along the simulated road's stretches, in three different runs. Subjects could see their speed on the speedometer visualized on the screen and they were free to choose the velocity, according to what the road scenario suggested to them. The scenario represented an highway geometry and it was performed with three different flow conditions as qualitatively indicated as: Low Interfering Flow (LIF), Medium Interfering Flow (MIF), High Interfering Flow (HIF). According to the strict procedure of simulation experiments, participants were required to complete a training simulation scenario for at least 10 minutes driving and between each scenario participants were allowed a short break. This break was intended to avoid as much as possible the fatigue effect of each driving period.

\subsection{Dynamic model}

\subsubsection{Powertrain, wheel base and general features}

A "medium class" gasoline vehicle (Euro IV compliant) has been considered in the present work, whose features are representative of a wide share of fleet vehicles. Its main features are summarised in Table 1. 
Table 1: $\quad$ Vehicle features.

\begin{tabular}{|c|c|}
\hline Engine type, displacement & Gasoline, 1.61 \\
\hline Mass & $1350 \mathrm{~kg}$ \\
\hline Active area in aero drag & $1.91 \mathrm{~m}^{2}$ \\
\hline Aerodynamic coefficient & 0.3 \\
\hline Tire width & $175 \mathrm{~mm}$ \\
\hline Gear ratios & $\mathrm{I}=3.1 ; \mathrm{II}=1.6 ; \mathrm{III}=1, \mathrm{IV}=0.7$ \\
\hline Axle gear ratio & 3.85 \\
\hline Powertrain & Automatic gearbox, integrated torque converter \\
\hline
\end{tabular}

\subsubsection{Engine model}

The gasoline engine features have been expressed in terms of characteristic maps, as regards mechanical torque, fuel consumption and gaseous raw emissions $\left(\mathrm{CO}, \mathrm{HC}, \mathrm{NO}_{\mathrm{x}}\right)$. During the simulations, depending on the road-traffic conditions and on the driver behaviour, the resulting engine operation point determines fuel consumption and raw emissions. Figure 2-Left and 2-Right report the used engine maps, which have been built on the basis of IFP-Drive Library provided in AMESim code [12].
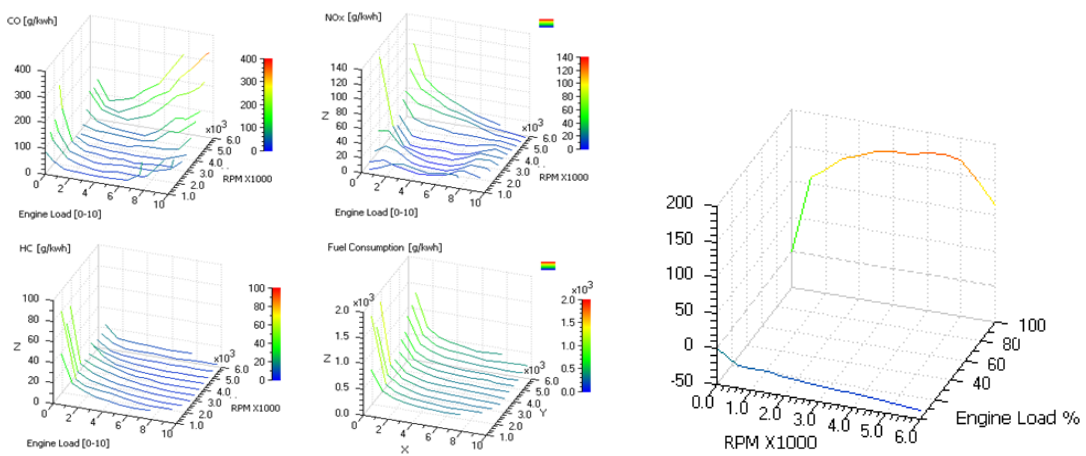

Figure 2: (Left) Engine specific emission and fuel consumption maps; (Right) Engine torque map.

\subsubsection{After treatment - Three Way Catalyst model}

On the basis of the discussed maps, the engine model is coupled to the TWC model and exhaust gases (carrying raw emissions) are treated. In this configuration, $\mathrm{NO}$ reduction and $\mathrm{CO}$ and $\mathrm{HC}$ oxidation are done in the same catalytic structure. Kinetic models are associated with reaction mechanisms. The reaction rates are of the Langmuir-Hinshelwood type. All kinetic constants $\left(\mathrm{k}_{\mathrm{i}}\right)$ are parameters of the TWC model and the used values are those available in the IFP-Exhaust library, provided with AMESim code [12]. The assumption that the kinetic constants follow an Arrhenius law is adopted. As the simulation is referred to highway-drive conditions, and as the engine does not experience the cold-to-hot transition, a zero-dimensional approach has been adopted. 


\subsection{Static model}

COPERT 4 model version 10.0 developed by EMISIA has been used [15]. This model estimates emissions of all major air pollutants $\left(\mathrm{CO}, \mathrm{NO}_{\mathrm{x}}, \mathrm{VOC}, \mathrm{PM}, \mathrm{NH}_{3}\right.$, $\mathrm{SO}_{2}$, heavy metals) produced by different vehicle categories as well as greenhouse gas emissions $\left(\mathrm{CO}_{2}, \mathrm{~N}_{2} \mathrm{O}, \mathrm{CH}_{4}\right)$. It also provides specification for $\mathrm{NO} / \mathrm{NO}_{2}$, elemental carbon and organic matter of PM and non-methane VOCs, including PAHs and POPs. In this paper, COPERT 4 has been used to calculate $\mathrm{CO}, \mathrm{HC}$ and $\mathrm{NO}_{\mathrm{X}}$ emission factors; as known, the worldwide gasoline vehicle emission standards are referred to these standard gaseous pollutants.

\section{Results an discussion}

\subsection{Drive style influence, average speed and fuel consumption}

Figure 3 shows the average speed values for each scenario, calculated by processing the speed profiles of each driver. The corresponding fuel consumption is also shown. The higher interference on the considered road stretches leaded to a lower average speed reducing fuel demand.
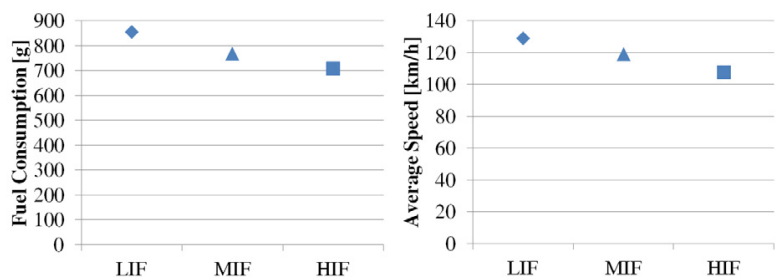

Figure 3: Total fuel consumption and average speed depending on flow condition.

From a quantitative point of view, the decrease of speed values between LIF and MIF is equal to $8 \%$ and between LIF and HIF is equal to $17 \%$. Consistent with this, in each scenario it was assessed an average fuel consumption decrease equal to $10 \%$, regarding the comparison LIF - MIF and LIF - HIF the decrease is equal to $17 \%$.

\subsection{Emissions}

Having in mind what was previously presented about fuel consumption, the results show how the decrease of consumption induced by driving style does not involve a general reduction in terms of pollutant emissions. The emissions average values, carried out for each drivers in the three different flow conditions, have been reported in Figure 4. 

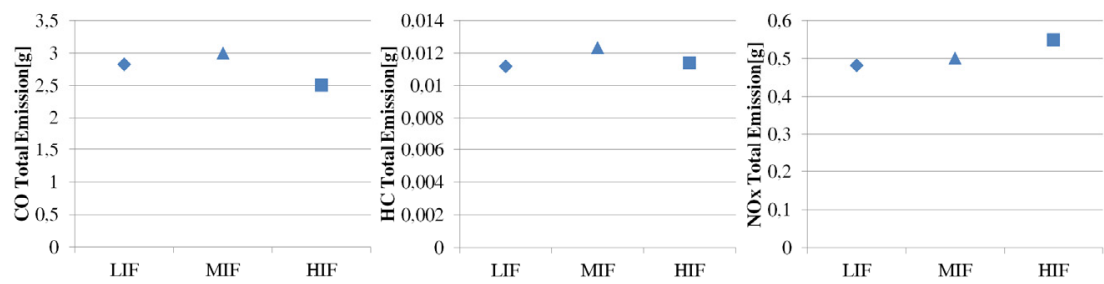

Figure 4: Pollutant emission depending on flow condition.

In particular, it was calculated an increase for each pollutant moving from LIF to $\mathrm{MIF}-\mathrm{CO}$ equal to $6 \%$, $\mathrm{HC}$ equal to $10 \%$, NOx equal to $5 \%$. Analysing the comparison between LIF and HIF it has been observed a CO value's decrease about $12 \%$-, an HC value's increase - about $2 \%$ - and an NOx value's increase - about $14 \%$.

It is important to underline that pollutants production strongly depend on several factors which are dependent on drivers maneuvers. This facet can be considered the strength of this approach. Indeed, Figure 5 shows the outline of some instantaneous indicators, such as speed profile and throttle influencing CO emission factor obtained during one of the driving tests; here it is possible to appreciate how the emission factor is highly variable, depending on the driving
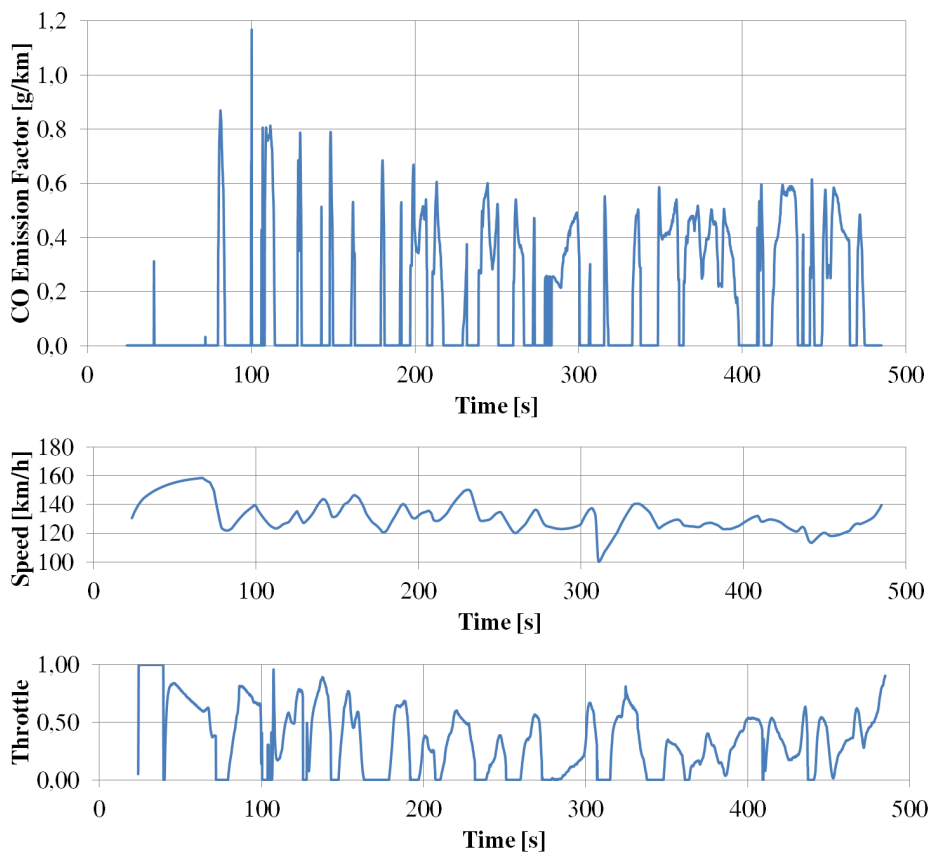

Figure 5: Example of driving style characterization. 
style. Moreover, Figure 5 points out the importance of analysing speed profile i.e. speed variation over the time - as well as average speed. Therefore in order to study the operating speed profile and to obtain more reliable emissions values, the assessment of the driving behaviour of each driver along each scenario may play a crucial role. According to De Blasiis and Guattari [19] the speed variations (in terms of acceleration and deceleration) increase when the vehicular interferences increase.

In the frame of the instantaneous model approach, the emission factor is computed directly taking the traffic condition (as in this case) or to the road features into account. Figure 6 shows the relation between emission factors $(\mathrm{CO}$, $\mathrm{HC}$ and $\mathrm{NO}_{\mathrm{x}}$ ) and instantaneous speed - performed by instantaneous model regarding one driver. In order to obtain the emission factors which represent the traffic condition on the considered stretch, it is important to evaluate the driving behaviour of each driver. In the present case, the coupling between the driving simulator and the complete vehicle model have provided the relation between the flow conditions and emission factors.

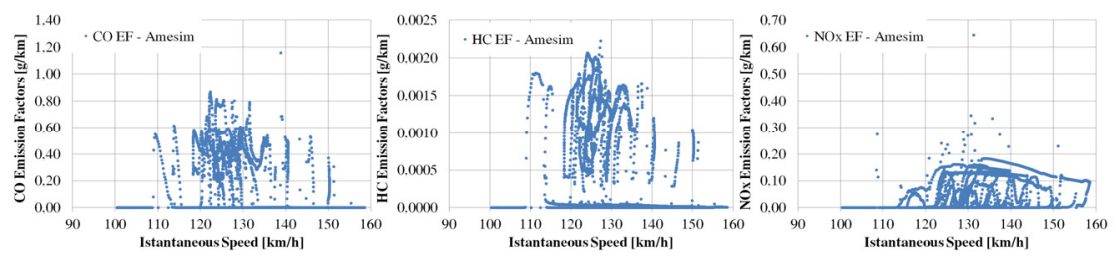

Figure 6: Instantaneous EFs calculated by AMESim code.

The common behaviour kept by the sample of drivers, according to different scenarios performed during the simulations, has been evaluated. The EFs prediction of the dynamic model are consistent with experiments based on PEMS (Portable Emissions Measurement System) reported in the literature, Kousoulidou et al. [20]; on the other hand, predictions based on COPERT 4 model overestimate $\mathrm{CO}$ and $\mathrm{HC}$ EFs, whereas, good agreement on NOx is found. This condition is represented in Figure 7, where the EFs as function of vehicle average speed are reported; the aforementioned differences are clearly visible.
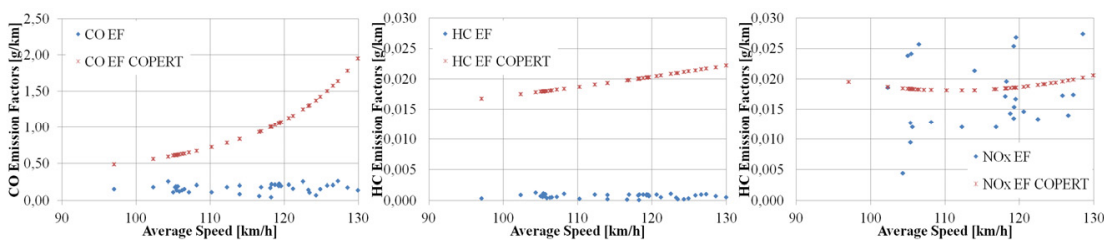

Figure 7: $\quad$ Comparison between COPERT 4 and AMESim model results. 


\section{Conclusions and future research}

In conclusion, this study approaches the topic of vehicle emission estimation analysing emission factors using a comprehensive simulation tool. Such a model has been built by coupling a driving simulator and a complete lumped parameter vehicle model, in which exhaust gas aftertreatment simulation is implemented. The model is used to highlight the influence of driving behaviour on fuel consumption and emission factors.

When the interfering flow increases, a reduction in terms of average speed and fuel consumption has been recorded, whereas the gaseous emission has shown a different trend.

It has been shown how emissions factors depend on operating speed profile. Comparing the results carried out by dynamic model with experimental ones assessed by PEMS starting from real-world operation data, a good correlation has been found. On the other hand, comparing outcomes of static model and dynamic model a different emission trend has been assessed.

Indeed static model trend shows that emissions increase when the speed increase - regarding the analysed speed range - , while, the implemented dynamic model does not provide a direct correlation between average speed and emissions factors, as they represent the complete vehicle operation conditions. Therefore, the average speed value should not be considered the only parameter representative of emission phenomenon but there is the need to consider drivers' behaviour and interfering flow influence. In order to study more in depth drivers' styles, different scenarios, in terms of different flow conditions, fleet of vehicles and geometrical design, will be further implemented.

\section{References}

[1] Ajtay, D., and Weilenmann, M., (2004), Vol. 22, No 3, Static and dynamic instantaneous emission modelling, International Journal of Environment and Pollution.

[2] Liu H., He K., Barth M., Traffic and emission simulation in China based on statistical methodology, Atmospheric Environment, 45(5), pp. 1154-1161, 2010 .

[3] Trozzi, C., Vaccaro, R., Crocietti, and S., Speed frequency distribution in air pollutants' emissions estimate from road traffic, The Science of the Total Environment, 189.190, pp. 181-185, 1996.

[4] Gense, N.L.J., Driving Style, Fuel Consumption and Tail Pipe Emissions, Final Report TRL, Transportation Research Board of International Academies, Washington D.C., 2000.

[5] Van Mierlo, J., E., Maggetto, G., Van de Burgwal, E., and Gense, R., Driving style and traffic measures - influence on vehicle emissions and fuel consumption, Journal of Automobile Engineering, Proceedings of the Institution of Mechanical Engineers, Part D, 218, pp. 43-50, 2004.

[6] Corsmeier, U., Imhof, D., Kohler, M., Kühlwein, J., Kurtenbach, R., Petrea, M., Rosenbohm, E., Vogel, B., and Vogt, U., Comparison of measured and 
model-calculated real-world traffic emissions, Atmospheric Environment, 39(31), pp. 5760-5775, 2005.

[7] Smit, R., Ntziachristos, L., and Boulter, P., (2010), Validation of road vehicle and traffic emission models - A review and meta-analysis, Atmospheric Environment, 44(25), pp. 2943-2953.

[8] de Haan, P., and Keller, M., Emission factors for passenger cars: application of instantaneous emission modelling, Atmospheric Environment, 34, pp. 4629-4638, 2010.

[9] Ajtay, D., Weilenmann, M., and Patrik, S., Towards accurate instantaneous emission models, Atmospheric Environment, 39(13), pp. 2443-2449, 2004.

[10] Int Panis L., Broekx S., and Liu R., Modelling instantaneous traffic emission and the influence of traffic speed limits, Science of the total environment, 371(1-3), pp. 270-285, 2006.

[11] Franco, V., Kousoulidou, M., Muntean, M., Ntziachristos, L., Hausberger, S., and Dilara, P., Road vehicle emission factors development: A review, Atmospheric Environment, 70, pp. 84-97, 2013.

[12] AMESim, Tutorials and User Guide, LMS, 2011.

[13] Chiatti, G., Chiavola, O. and Palmieri, F., "Phenomenological Approach for Common Rail Diesel Engine Emission and Performance Prediction", SAE Paper 2010-01-0874, 2010.

[14] Chiatti, G., Chiavola, O. and Palmieri, F., "Modeling the Effect of Nozzle Hole Geometry on Diesel Injection and Combustion", ASME ICEF Paper $35067,2010$.

[15] COPERT 4 Computer programme to calculate emissions from road transport, User Manual (version 10.0), EMISIA / EEA COPERT 4, 2012.

[16] Bella F., Validation of a driving simulator for work zone design, Transportation Research Record: Journal of the Transportation Research Board, 1937, pp. 136-144, 2005.

[17] Benedetto C., De Blasiis M.R, and Benedetto A., Driving simulation based on approach for quality control of road projects, Advances in Transportation Studies, an International Journal, 1, pp. 86-96, 2003.

[18] Benedetto C., Il progetto della strada sicura: la ricerca sperimentale in realtà virtuale, Aracne, 1, 2002.

[19] De Blasiis, M.R., and Guattari, C., About the potentialities of virtual reality simulation in the analysis of unsteady traffic flows, Proc. of the 1st Int. Conf. Road Safety and Simulation, Rome, 2007.

[20] Kousoulidou, M., Fontaras, G., Ntziachristos, L., Bonnel, P., Zissis Samaras, Z., and Dilara, P., Use of portable emissions measurement system (PEMS) for the development and validation of passenger car emission factors, Atmospheric Environment, 64, pp. 329-338, 2013. 